has met with another disaster in the death, from dysentery, of $M$. Wautier, at a place called Kekongen (? Ukonongo). On the other hand, Major Pinto, the leader of the Portuguese African expedition, telegraphs to Lisbon from Pretoria, that he has virtually crossed Africa from the west coast, after struggling with hunger, thirst, beasts, natives, floods, drought. His route must have to some extent almost coincided with that of Livingstone, and he tells us he has saved all his papers, twenty geographical charts, many topographical maps, several vols. of notes, drawings, meteorological data, a diary of the exploration of the Zambesi's seventy-two cataracts and rapids. He says he has discovered the secret of the Cubango, by which he seems to mean the river which, under various names, was for a time taken by some to be the upper course of the Congo. He lost many followers, and his expedition seems in a small way to have been modelled on that of Stanley's.

THE Times Roman correspondent writes that Menotti Garibaldi and Achille Fazzari intend, if England does not object, to sail in summer or autumn with 3,000 Italians for the south coast of New Guinea, to establish a colony there, and found a new city under the name of Italia. The arrangements, it is said, are almost completed, the $30,000,000$ francs required ready, and that applications to join the party are more than can be granted. Part of the equipment will be a telegraph cable, to place the colony at once in communication with North Australia. Men of all ranks and callings (except lawyers) are included in the party, and among them several men of science. The proposed colonists express the greatest good will towards England, and it seems to us the trial would be worth making. The Italians make better colonists than the French, and Italians have done so much for the exploration of New Guinea that it seems only fair that they should be allowed to reap some benefit from the labours of such men as D'Albertis and Beccari.

AT the last meeting of the Société Commerciale de Géographie at Paris Dr. Raffray gave some particulars respecting his recent explorations in New Guinea, and called attention to the fact that that country offered a vast field for discovery and study to the traveller, especially from an ornithological and entomological point of view. A report on the subject of a railway across the Desert of Sahara was afterwards read, being the result of the labours of a committee, of which M. Gazeau de Vautibault is president. M. Deloncle also made a communication respecting the Volta region in West Africa, which has been explored by $M$. Bonnat, and he announced that two Lyons merchants had already determined to establish business houses there.

MGR. LAVIGERIE, Archbishop of Algiers, has forwarded to Les Missions Catholiques the commencement of the journal of the Algerian missionaries, recording the incidents of their march towards the Nyanzas and Lake Tanganyika. This portion of their journal stops at Mukuduku in Ugogo on August 20, and the first instalment of this is now published. It had been intended to accompany it by a map of Equatorial Africa, sent home by Père Charmetant some time back, but it has been thought better to delay the publication, in order that the itinerary of the missionaries and the additional geographical information contained in their journal may be included in it.

IT is stated in an Italian newspaper that the Duke of Genoa will go on an exploring expedition, and will sail from Venice in the Vittore Pisani at the end of this month. The programme of the route is to be Port Said, Suez, Aden, Ceylon, and Singapore, where a longer sojourn will be made. Afterwards the traveller will proceed to the Chinese and Japanese coasts; in 1880 he will visit Australia and direct his special attention to the exploration of New Guinea. On the return journey the
Pisani will cruise in the Persian Gulf. Capt. Sebastian and Count Antonela have started on an exploring tour
through Africa.

A POSTCARD was received at Berlin on February 15 from Dr. Gerhard Rohlffs, dated January 27 and posted at Sokna, some 250 miles south of Tripolis, at the foot of the Black Mountains, stating that he was in perfect health. The postcard bears the stamp of Dr. Rohlff's desert post, and a prettily-drawn postage-stamp with African palm-leaves.

To accompany the map of Zululand, noticed last week, Mr. Stanford has published a few useful notes on the physical features and population of the country.

THE Jeannette is fitting up in San Francisco harbour, and will leave for polar exploration in the month of June. Mr. Bennett, who is now in Europe, has been making inquiry at Paris as to the best means of constructing and inflating balloons in the Arctic regions. It is thus likely that aërial navigation will play a part in this new effort to solve the mystery of the north.

\section{EDISON'S TELEPHONE}

$\mathrm{O}$ $\mathrm{UR}$ readers may remember a few months ago we stated, in an article on the Carbon Telephone (NATURE, vol. xix. p. 56), that Mr. Edison had devised an entirely new form of receiver, for use with his telephone, which delivered the voice as loudly as if the words were spoken at the distant end. This receiver has now arrived in England in charge of Mr. Edison's nephew, and to judge from its performances last Friday, it is likely to accomplish all that Edison has stated concerning it.

The principle of this new receiver is that of the electromotograph, and to those of our readers who may not be acquainted with this instrument the following extract from a recently published lecture, on Edison's inventions, by Prof. Barrett will explain what the electro-motograph is. ${ }^{1}$

"Mere ingenuity in contriving machines does not add to the sum of human knowledge, and if $\mathrm{Mr}$. Edison were merely a clever inventor and nothing morc, I should feel less interest in the man. It is, however, a nuticeable fea ture of Mr. Edison's inventions that they, in general, contain some new principle, some original observation in experimental science, which entitles him to the rank of a discoverer. Such is the character of the next invention we must consider, the so-called electro-motograph. This is an entirely new method of receiving telegraphic messages, discovered by Edison in 1874 . As every one is aware, the ordinary system of telegraphy depends upon the production of magnetism by means of an electric current, the current either attracting and releasing a movable piece of iron, or deflecting a magnetic needle to the right or to the left. By the to-and-fro movements of the iron or the needle the conventional signals are produced which are employed in telegraphy. Now Mr. Edison made the curious and important discovery that messages could be received by the well-known Morse recorder without the use of any magnet. This, to a telegraphist, would be like attempting to perform the play of "Hamlet," while omitting the part of Hamlet himself. In fact, all that is necessary in this simple telegraphic instrument is a band of moistened paper drawn beneath a metal style. The accident of holding his finger against the style of a Morse instrument led Mr. Edison to notice that when an electric current passed from the paper to the point resting upon it the friction of the moving paper was lessened. Hence, if the paper were drawn with a uniform force it would slip more easily beneath the point the moment the current passed. The slipping of the x "Science Lectures for the People," No. 5, Tenth Series. (Manchester,
Heywood.) 
paper is converted into a to-and-fro motion of a lever to which the point is attached, and which is made to actuate a bell, or "sounder," and give rise to audible signals in the usual way. It is necessary to moisten the paper with a solution of certain chemicals. Potash was at first used, but a solution of sulphate of soda or of common salt and pyrogallic acid is found to be best. ${ }^{1}$

"The advantage of this instrument, which Mr. Edison calls an electro-motograph, is said to be its extreme sensitiveness, it having been worked over a circuit of two hundred miles with only two cells, so that with weak currents, unable to affect ordinary instruments; the electro-motograph can receive messages. More than this, the speed of its working is greater than with the ordinary instruments. Using it as a relay, that is, an instrument for translating weak currents into strong ones, no less than $\mathbf{J}, 200$ words per minute have been transmitted by its means, or five times as fast as it is possible for any person to read the message which comes through the instrument. So prompt and delicate is the motion of this machine that Edison has applied it to the purposes of the receiving instrument for the Reiss telephone, a musical telephone that was made many years ago. The slipping of the paper causes a slight sound. If, then, we sing a certain note into the Reiss transmitting instrument, which vibrates in unison with that note, we obtain the same number of electric currents produced per second as we had of sonorous vibrations in the moving diaphragm. Thus, if we sounded the middle $C$ we should get 264 vibrations, and there would be 264 electric currents, and 264 slips of the paper, thus producing a note of the same pitch in a distant room. The cause of the curious slipping has not been fully ascertained. It may possibly be due to that peculiar repulsive effect to which.Mr. Crookes has lately drawn attention, and which produces the dark region around the negative electrode during the continuance of an electric discharge in a vacuum tube, or it may simply be due to electrolytic action."

It is, then, this principle which Edison has made use of in his new receiver, which is of the simplest construction. A diaphragm, preferably of mica, some four inches in diameter, held in a suitable framework, has attached to its centre a spring, or "pawl," the free end of which rests on a little cylinder of chalk, capable of rotation by the hand or other means. The chalk cylinder replaces the paper in the electro-motograph, and is necessarily impregnated with sulphate of soda, or other suitable solution. As the cylinder is rotated, the friction of the spring on the chalk causes the diaphragm to be pulled in or pushed outwards, according to the direction of the rotation. So far the operation is purely mechanical ; as soon, however, as the current passes, either owing to electrolytic action or the friction, it is lessened, and the diaphragm tends to spring back to its normal position; on the cessation of the current the friction is restored, to be lessened on the recurrence of another electric wave. Thus, a series of tremors are given to the diaphragm corresponding to the swiftly changing character of the clectric waves, and these again faithfully express the motion of the diaphragm at the transmitting end. It will thus be evident that the incoming current has simply to do the work of liberating the already strained diaphragm. As everyone knows, in Bell's telephone the voice has to do the work of creating the current at the transmitting end, and the feeble magneto-electric currents thus generated throw into motion the diaphragm at the receiving end. In Edison's telephone this is not so. The voice at the transmitting end bas simply to vary the electric resistance in the path of a current generated by an ordinary voltaic battery; stronger currents can thus be sent along the line, and these arriving at the receiving end, have merely to vary a mechanical resistance, and

Practical difficulties have, we believe, been found in the working of the motograph, so that it has not come into telegraphic use. not to do the work of overcoming the inertia of the diaphragm. It is probable the rotating chalk cylinder acts on the diaphragm with its attached spring like a resined bow on a violin string; vibrations are set up, the extent, rate, and manner of which are modified by the varying friction due to the telephonic currents. Whether these new receivers will retain their present efficacy when in constant use remains to be seen. We should be inclined to think the soft surface of the chalk will eventually wear with the friction, and that a more permanent arrangement will have to be devised. No invention, however, reaches perfection at once, and the present receivers, excellent as is their performance, were, we understand, hastily made in a few days, in compliance with the urgent request of Mr. Edison's courteous representative in London, Col. Gouraud.

The instrument has the appearance of a small box. attached to the wall, and from which there projects a single funnel. Sounds of singing, speaking, whistling, sent from the other end, quite a mile off, were heard in every part of a moderately sized room. Telephonic connections, now so common in America, have been established by Col. Gouraud between various business houses in the city; and we believe that shortly this method of communication must become quite common.

\section{NOTES}

Dr. Miclucho Maclay, the eminent Russian Naturalist and New Guinea explorer, has been trying to rouse the Linnean Society of New South. Wales and the scientific public of Sydney to the necessity of founding a zoological station, similar to that at Naples. He tells of the great inconvenience he himself has suffered during his residence at Sydney from the want of such a station, even though the Hon. Mr. Macleay placed his museum at his disposal. But Dr. Maclay's scheme embraces much more than a station at Sydney. He has written to the German Eastern Asiatic Society at Japan and to Mr. August Godeffroy at Samoa, urging that similar stations be founded at these placès, and he has reason to believe that his proposals will not be without result at both places. Thus should zoological stations be instituted at Sydney, in New Zealand (as Dr. Maclay also proposes), in Japan, and at Samoa, we might hope in a very few years to have a fairly com. plete knowledge of the fauna of the Pacific. Dr. Maclay's proposal deserves the heartiest encouragement, and we trust that ere long it will be fully carried out. We hope the people of Sydney, at any rate, will take Dr. Maclay's appeal to heart ; he tells them, moreover, that he will judge of the intensity of the scientific life of Australia by the interval which elapses between the reading of his paper on the subject and the actual foundation of the station. He shows what valuable results have followed the foundation of the Naples station, and gives a few hints as to how such a station at Sydney should be organised. We shall be curious to see what will be the result of Dr. Maclay's fervent appeal.

WE are requested to state that on and after April I any person may obtain by telegraph from the Meteorological Office the latest information as to the weather in any district of the United Kingdom by payment of a fee of $\mathbf{I} s$. in addition to $2 s$. the cost of the message to the Meteorological Office and the reply. The telegram containing the inquiry must not exceed twenty words in length, and must be addressed, " Meteorological Office, London." The Meteorological Office does not undertake to give any information which is not substantially included in the latest notice posted at its own doors, nor does it give forecasts of the weather on the Atlantic coasts of the British Isles; althongh it is ready to furnish any information it possesses as to the actual state of the weather on those coásts. The Meteoro. logical Office is open for such inquiries between the hours of 